\title{
Colonic tuberculosis clinically misdiagnosed as anorexia nervosa, and radiologically and histopathologically as Crohn's disease
}

Tariq A Madani MD

TA Madani. Colonic tuberculosis clinically misdiagnosed as anorexia nervosa, and radiologically and histopathologically as Crohn's disease. Can J Infect Dis 2002;13(2):136-140.

A case of colonic tuberculosis presenting with severe wasting was misdiagnosed as anorexia nervosa at another institution. Double contrast barium enema showed strictures, and ulcerations of the cecum and ascending colon with a skip area. The radiologist believed that these findings were due to Crohn's disease. Colonoscopic biopsies from the involved area revealed histopathological changes typical of Crohn's disease and not tuberculosis. The patient completely recovered with antituberculous therapy without steroids. The case demonstrated the clinical, radiological and histopathological difficulties and misdiagnoses that may be associated with the diagnosis of colonic tuberculosis.

Key Words: Anorexia nervosa; Colon; Crohn's disease; Tuberculosis
Tuberculose du côlon diagnostiquée à tort cliniquement comme de l'anorexie nerveuse, radiologiquement et histopathologiquement comme la maladie de Crohn

RÉSUMÉ : Voici un cas de tuberculose du côlon se manifestant sous forme de cachexie grave, qui a été diagnostiqué à tort comme de l'anorexie nerveuse dans un autre établissement. Un lavement baryté à double contraste a montré la présence de rétrécissements et d'ulcérations du caecum et du côlon ascendant avec distribution discontinue des lésions. Le radiologiste a cru qu'il s'agissait de lésions dues à la maladie de Crohn. Les biopsies effectuées dans la région touchée ont révélé des changements histopathologiques caractéristiques de la maladie de Crohn, non de la tuberculose. Le patient, soumis ensuite à un traitement antituberculeux sans stéroïdes, s'est rétabli complètement. Le cas illustre bien les difficultés cliniques, radiologiques et histopathologiques et les risques de diagnostic erroné que peut comporter la reconnaissance de la tuberculose du côlon.

King Abdulaziz University Hospital, Jeddah, Saudi Arabia

Correspondence: Dr TA Madani, Department of Medicine, King Abdulaziz University Hospital, PO Box 80215 ,

Jeddah 21589, Saudi Arabia. Telephone +966-5-568107, +966-2-6702324, +966-2-6408243, fax +966-2-6403975,

e-mail tmadani@hotmail.com

Received for publication November 23, 2000. Accepted April 19, 2001 
C olonic tuberculosis, albeit uncommon, remains an important diagnostic consideration in any patient presenting with diarrhea, abdominal pain or unexplained weight loss. This diagnosis, however, can be challenging and difficult to differentiate from Crohn's disease or other causes of weight loss. The author describes a case of colonic tuberculosis that was misdiagnosed clinically as anorexia nervosa, and the radiological and pathological features were misinterpreted as Crohn's disease.

\section{CASE PRESENTATION}

A 30-year-old, single, female Pakistani obstetrics and gynecology resident working in a western country was seen in August 1998 in the author's outpatient clinic because of a five-month history of general malaise, anorexia, weight loss of $14 \mathrm{~kg}$, nonself-induced vomiting, abdominal pain and occasional diarrhea. The diarrhea was intermittent, consisted of three to four bowel movements of semiformed stools per day with no mucus, blood or tenesmus, and was usually preceded by colicky abdominal pain that abated with defecation. She had also had a fever of $38^{\circ} \mathrm{C}$ to $39^{\circ} \mathrm{C}$ associated with chills, particularly at night, for the preceding two months. Apart from bronchiectasis diagnosed three years before presentation, the patient had no other medical illnesses. She had no history of tuberculosis nor recent exposure to the disease. The patient had been working as a senior resident in obstetrics and gynecology. Over the preceding two months, she had been unable to continue working because of severe lassitude and wasting. She was evaluated in the hospital in which she was working and underwent investigations, which did not reveal anything of significance. She was diagnosed as having anorexia nervosa, and follow-up with a psychiatrist was arranged. She was also treated with several courses of antibiotics for what was thought to be exacerbation of bronchiectasis with no defervescence. Because of the progressive deterioration of her general condition, the patient went to live with her

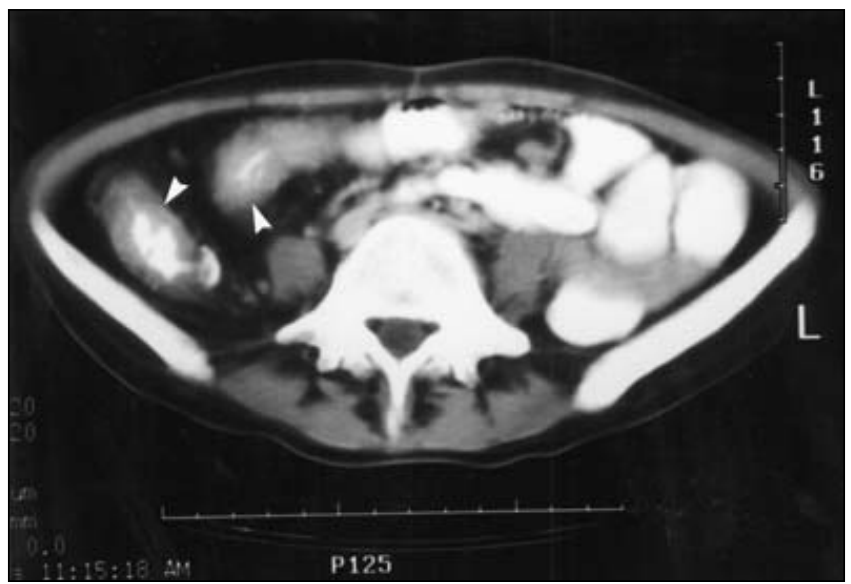

Figure 1) Computed tomography scan of the abdomen showing circumferential uniform thickening of the wall of the bowel (arrowheads) parents who were living in Jeddah, Saudi Arabia, and was seen in the author's clinic for a second opinion.

On examination, the patient was pale and very cachectic, weighing $27 \mathrm{~kg}$ with a height of $145 \mathrm{~cm}$. Her pulse rate was 80 beats/min, blood pressure was 100/60 mmHg, respiratory rate was 18 breaths $/ \mathrm{min}$ and temperature was $38^{\circ} \mathrm{C}$. She was unable to walk without support because of general weakness and wasting. She had oral thrush and digital clubbing. Abdominal examination revealed a soft abdomen with no organomegaly, palpable masses or tenderness. Bowel sounds and rectal examination were normal. The rest of the examination was normal.

The patient was admitted to the hospital, where investigations revealed a hemoglobin level of $8.8 \mathrm{~g} / \mathrm{dL}$; mean corpuscular volume of $79.5 \mathrm{fL}$; white blood cell count of $7.9 \times 10^{9} / \mathrm{L}$ with $66 \%$ neutrophils, $31 \%$ lymphocytes, $1 \%$ monocytes and $0.6 \%$ eosinophils; platelet count of $430 \times 10^{9} / \mathrm{L}$; erythrocyte sedimentation rate of $195 \mathrm{~mm} / \mathrm{h}$; normal electrolyte, creatinine and glucose levels; total protein level of $59 \mathrm{~g} / \mathrm{L}$; albumin level of $28 \mathrm{~g} / \mathrm{L}$; and normal liver enzymes and bilirubin levels. Tests for HIV and antinuclear antibodies were negative. The stool analysis was positive for occult blood and Entamoeba histolytica trophozoites, for which the patient received metronidazole; there was no improvement in diarrhea. Stool and blood cultures were negative. Tuberculin skin test with $5 \mathrm{U}$ of purified protein derivative was positive, with $15 \mathrm{~mm}$ induration. Chest radiograph showed a collapsed bronchiectatic apical segment of the left lower lobe, which was confirmed by a computed tomograghy (CT) scan of the chest. A CT scan of the abdomen showed circumferential uniform thickening of the wall of the cecum and ascending colon (Figure 1), with normal terminal ileum (Figure 2), fatty liver changes, mild splenomegaly and no ascites or enlarged retroperitoneal lymph nodes. Small bowel enema revealed that the ileum and jejunum were well distended, with a normal mucosal pattern, but the cecum and ascending colon, which were vaguely visualized, were noted to be abnormal

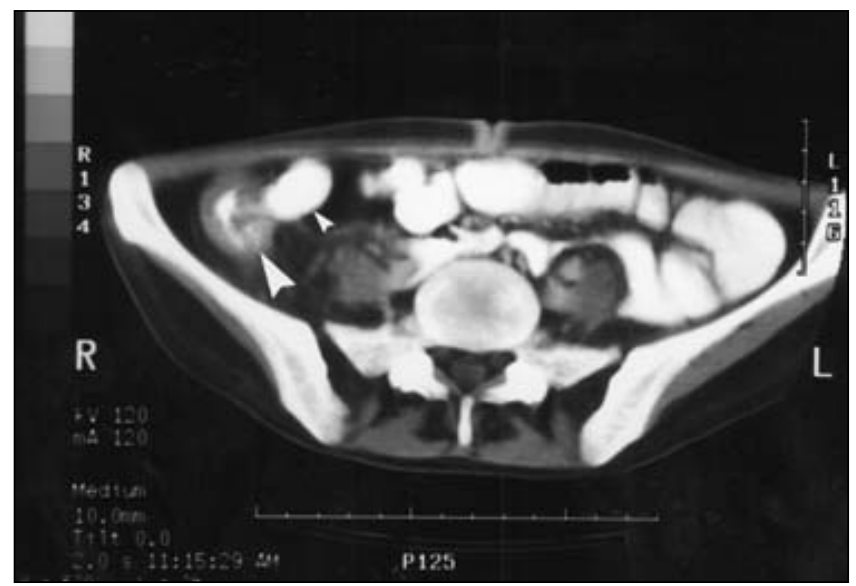

Figure 2) Computed tomography scan of the abdomen showing the ileocecal junction with a normal terminal ileum (small arrowhead) and thickening of the wall of the cecum (large arrowhead) 
and narrow. The first colonoscopy eight days after admission revealed an entirely normal colon according to the colonoscopist. At this point, and because of the strongly suspected colonic tuberculosis and the patient's poor general status, antituberculous therapy with isoniazid, rifampin, ethambutol and pyrazinamide was started nine days after admission. Subsequently, the patient had a double contrast barium enema that showed that the cecum was completely deformed, narrowed, cone-shaped and rigid, with multiple, asymmetrically distributed ulcers. The abnormalities extended up and involved the ascending colon with a skip area (Figure 3), followed by a narrowed rigid segment involving the rest of the ascending colon, hepatic flexure and the proximal part of the transverse colon, with typical 'collar button' ulcers, and deeper linear transverse and longitudinal ulcers. The ileocecal junction and the rest of the colon were normal. In the radiologist's opinion, Crohn's disease was the most likely diagnosis, and tuberculosis was less likely. Colonoscopy was then repeated by the same colonoscopist 21 days after admission. The colon was described to be very redundant. Eighty centimetres from the anal verge, a severe stricture with ulcerations of the mucosa and granular projections were encountered. The scope could not be advanced further. Multiple biopsies were obtained for histopathological examination and mycobacterial culture. Histopathological examination revealed multiple fragments of large bowel mucosa exhibiting extensive infiltration of the lamina propria by mixed inflammatory cells, including eosinophils and occasional polymorphs with multiple noncaseating granulomata. Focal ulceration of the surface was noted. The inflammation extended beyond the muscularis mucosa. Focal areas of cryptitis with crypt abscesses were noted. Collections of epithelioid macrophages without necrosis were present. No dysplastic changes were noted. Three experienced pathologists unanimously diagnosed inflammatory bowel disease with noncaseating granulomata consistent with Crohn's disease. The tissue biopsies for mycobacterial culture, submitted 12 days after starting antituberculous therapy, were negative after two months of incubation.

The patient was diagnosed as having colonic tuberculosis based on the clinical presentation (wasting, diarrhea and fever), a strongly positive tuberculin test, and the radiological and pathological evidence that may also be consistent with tuberculosis. The oral thrush was attributed to the receipt of several courses of antibiotics, and the immunosupression was associated with the general wasting due to intestinal tuberculosis. Digital clubbing was attributed to her known bronchiectasis. The patient rapidly improved on antituberculous therapy. Fever and diarrhea completely resolved seven and 12 days after commencing therapy, respectively, and her general condition and appetite also improved. She was discharged after three weeks of hospitalization in good general condition. The patient returned back to her country and resumed work four weeks after hospital discharge. On follow-up, she continued to feel well, and by the end of six months, she was back to her normal

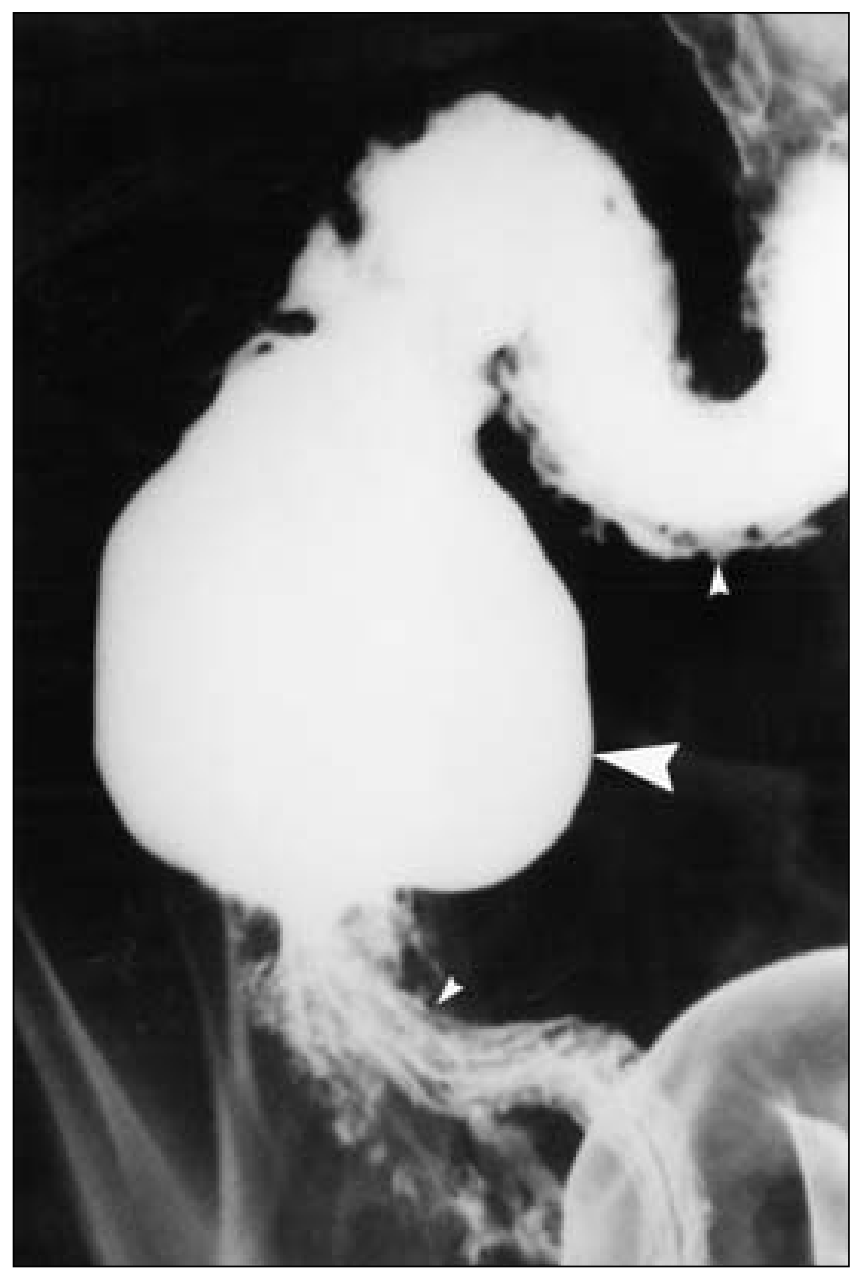

Figure 3) Double contrast barium enema showing two strictures with mucosal ulcerations (small arrowheads) in the ascending colon and hepatic flexure with a skip area in between (large arrowhead)

body weight of $51 \mathrm{~kg}$, her hemoglobin level increased to $13.5 \mathrm{~g} / \mathrm{L}$, her erythrocyte sedimentation rate declined to $10 \mathrm{~mm} / \mathrm{h}$ and her albumin level increased to $43 \mathrm{~g} / \mathrm{L}$. Antituberculous therapy with isoniazid, rifampin, ethambutol and pyrazinamide, along with pyridoxine, were given for two months, followed by isoniazid and rifampin with pyridoxine for seven more months. Twelve months after discontinuing antituberculous therapy, the patient continues to feel well and is leading a normal life.

\section{DISCUSSION}

This case demonstrates how readily colonic tuberculosis may be missed or misdiagnosed. Several caveats are worth mentioning. This patient, who had severe wasting, was misdiagnosed as having anorexia nervosa despite the presence of other symptoms suggestive of an organic disease, namely, fever and diarrhea. Digital clubbing favoured a diagnosis of Crohn's disease over colonic tuberculosis, but the patient was known to have bronchiectasis, which had likely caused the digital clubbing. Radiologically, the skip lesion led the radiologist to favour Crohn's disease over 
tuberculosis. Based on histopathological evidence, three experienced pathologists unanimously diagnosed Crohn's disease and confidently believed that tuberculosis was unlikely. The lesion was missed on the first colonoscopy, because the scope could not be advanced far enough through the markedly long and tortuous colon. Despite such pitfalls, colonic tuberculosis was diagnosed on the bases of clinical presentation, a strongly positive tuberculin test, and the radiological and histopathological results that could also be consistent with this disease. A CT scan of the abdomen showed thickening of the bowel mucosa, which was the first clue to the diagnosis. A double contrast barium enema study was the most useful imaging technique, clearly delineating the abnormalities.

The long-recognized similarities between intestinal tuberculosis and Crohn's disease led to the hypothesis that Crohn's disease may also be due to a mycobacterial infection (1). Mycobacterium paratuberculosis, the causative agent of chronic granulomatous enteritis (Johne's disease) in animals, has been particularly implicated as a possible cause of Crohn's disease. The organism was cultured from involved tissues of some patients with Crohn's disease (2-6), but an etiological role has been difficult to confirm because of the difficulty of microbiological identification by conventional methods. Additionally, the very close similarity of this organism with Mycobacterium avium, a species ubiquitous in the environment and therefore in the human gut, adds to the difficulty of microbiological isolation and identification (7). Another approach recently developed to avoid such difficulties is to amplify a DNA sequence specific to M paratuberculosis (IS900) using a molecular biology technique such as polymerase chain reaction. A strong relation has been found between the IS900 DNA sequence and Crohn's tissues (8-12). On the other hand, other studies have cast doubts on the relevance of the detection of the IS900 DNA sequence to Crohn's disease $(7,13)$. Clinical trials of antimycobacterial treatment have also yielded conflicting results. For instance, Swift et al (14) failed to show any favourable effect of two years of therapy with isoniazid, rifampicin and ethambutol in Crohn's disease. However, treatment directed more specifically at $M$ paratuberculosis has produced encouraging results $(15-17)$. Because of these somewhat conflicting results, the relevance of detecting mycobacterial DNA fragments in Crohn's tissues remains controversial and is not yet established.

The diagnosis of colonic tuberculosis can be challenging. A high index of suspicion is necessary to avoid missing such an important and curable disease. Double contrast barium enema studies are the most useful initial investigations to define bowel abnormalities. The most frequent site of intestinal tuberculosis is the cecum ( $85 \%$ to $90 \%$ ). In a Korean study that retrospectively defined the findings of tuberculous colitis after double contrast barium enema examination in 25 patients, the lesion was noted more commonly in the ascending colon, cecum and terminal ileum. Skip lesions were seen in 13 patients. Other features included multiple ulcers (16 patients), inflammatory polyposis (12 patients), fistulas (two patients), and thickening (five patients), deformity (six patients) and incompetence (eight patients) of the ileocecal valve (18). Ileal involvement can result in thickening of the bowel wall and narrowing, which can have the appearance of Crohn's disease (19). A CT scan can also be useful in detecting bowel wall or mesenteric thickening, enlarged mesenteric lymph nodes, omental masses and ascites, which can be associated with abdominal tuberculosis (20).

Colonoscopy is essential for direct visualization of the abnormalities and to obtain tissue biopsies to confirm the diagnosis. In one Indian study describing the colonoscopic features of colonic tuberculosis in 50 patients, the features included ulcers (92\%), nodules $(88 \%)$, deformed cecum and ileocecal valve (42\%), strictures (25\%), multiple fibrous bands (8\%) and polypoid lesions (6\%). Segmental tuberculosis and lesions simulating carcinoma were seen in $22 \%$ and $16 \%$ of the patients, respectively (21). In the present case, the colon was long and tortuous, which meant that the abnormalities were missed on the first colonoscopy. Upon confirming the involvement of the cecum and ascending colon with a double contrast barium enema study, colonoscopy was repeated, disclosing the abnormalities $80 \mathrm{~cm}$ from the anal verge.

Abdominal pain, fever, anorexia, weight loss and diarrhea are the most common symptoms of intestinal tuberculosis (21). Most patients also have pulmonary disease (22). Fever, weight loss, abdominal pain or pulmonary disease may be absent, however, making such a disease a diagnostic challenge in patients with intestinal tuberculosis $(23,24)$.

The histopathological features of intestinal tuberculosis can be easily confused with Crohn's disease, as demonstrated by the present case. Therefore, clinicians should not rely on the pathological diagnosis of Crohn's disease and should always consider tuberculosis as an important alternative diagnosis, particularly in patients from high risk countries. When in doubt, a trial of antituberculous therapy without steroids is warranted.

\section{CONCLUSIONS}

The present case demonstrated the clinical, radiological and histopathological difficulties that may be associated with the diagnosis of colonic tuberculosis. Physicians should maintain a high index of suspicion of this disease in any patient presenting with wasting syndrome, chronic diarrhea and fever. Physicians should also rely on the overall assessment of patients, particularly with regard to the clinical presentation, and should not be misled by radiological or pathological results that are not consistent with the clinical presentation.

ACKNOWLEDGEMENTS: The author thanks Dr Mohammed Neimatullah, Consultant Radiologist, King Abdulaziz University Hospital, Jeddah, Saudi Arabia, for his assistance in obtaining photographs of the images. 


\section{REFERENCES}

1. Crohn BB, Ginzburg L, Oppenheimer GD. Regional ileiitis, a pathologic and clinical entity. JAMA 1932;99:1323-9.

2. Chiodini RJ, Van Kruiningen HJ, Thayer WR, Merkal RS, Coutu JA. Possible role of mycobacteria in inflammatory bowel disease. I. An unclassified Mycobacterium species isolated from patients with Crohn's disease. Dig Dis Sci 1984;29:1073-9.

3. Chiodini RJ, Van Kruiningen HJ, Thayer WR, Merkal RS, Coutu JA. Characteristics of an unclassified Mycobacterium species isolated from patients with Crohn's disease. J Clin Microbiol 1984;20:966-71.

4. Coloe P, Wilks CR, Lightfoot D, Tosolini FA. Isolation of Mycobacterium paratuberculosis in Crohn's disease. Aust J Microbiol 1986; 7(Suppl):188A.

5. McFadden JJ, Butcher PD, Chiodini R, Hermon-Taylor J. Crohn's disease-isolated mycobacteria are identical to Mycobacterium paratuberculosis, as determined by DNA probes that distinguish between mycobacterial species. J Clin Microbiol 1987;25:796-801.

6. Gitnick G, Collins J, Beaman B, et al. Preliminary report on isolation of mycobacteria from patients with Crohn's disease. Dig Dis Sci 1989;34:925-32.

7. Rowbotham DS, Mapstone NP, Trejdosiewicz LK, Howdle PD, Quirke P. Mycobacterium paratuberculosis DNA not detected in Crohn's disease tissue by fluorescent polymerase chain reaction. Gut 1995;37:660-7.

8. Sanderson JD, Moss MT, Tizard MLV, Hermon-Taylor J. Mycobacterium paratuberculosis DNA in Crohn's disease tissue. Gut 1992;33:890-6.

9. Filder HM, Thurrell W, Johnson NM, Rook GA, McFadden JJ. Specific detection of Mycobacterium paratuberculosis DNA associated with granulomatous tissue in Crohn's disease. Gut 1994;35:506-10.

10. Ibboston JP, Filder H, Chahal H, Mussaddeq Y, Allan RN, McFadden JJ. Detection by polymerase chain reaction of Mycobacterium paratuberculosis-specific DNA in Crohn's disease tissues. Gut 1994;35:A165. (Abst)

11. Dell'Isola B, Poyart C, Goulet O, et al. Detection of Mycobacterium paratuberculosis by polymerase chain reaction in children with Crohn's disease. J Infect Dis 1994;169:449-51.
12. Mishina D, Katsel P, Brown ST, Gilberts EC, Greenstein RJ. On the etiology of Crohn disease. Proc Natl Acad Sci USA 1996;93:9816-20.

13. Suenaga K, Yokoyama Y, Okazaki K, Yamamoto Y. Mycobacteria in the intestine of Japanese patients with inflammatory bowel disease. Am J Gastroenterol 1995;90:76-80.

14. Swift GL, Srivastava ED, Stone R, et al. Controlled trial of anti-tuberculous chemotherapy for two years in Crohn's disease. Gut 1994;35:363-8.

15. Graham DY, Al-Assi MT, Robinson M. Prolonged remission in Crohn's disease following therapy for Mycobacterium paratuberculosis infection. Gastroenterology 1995;108:A826. (Abst)

16. Rubin PH, Chapman ML, Scherl E, Sachar DB, Stamaty C, Present DH. Clarithromycin in active Crohn's disease (CD): preliminary results of open label pilot study. Gastroenterology 1996;110:A1005. (Abst)

17. Gui GPH, Thomas PRS, Tizard MLV, Lake J, Sanderson JD, Hermon-Taylor J. Two-year-outcomes analysis of Crohn's disease treated with rifabutin and macrolide antibiotics. J Antimicrob Chemother 1997;39:393-400.

18. Han JK, Kim SH, Choi BI, Yeon KM, Han MC. Tuberculous colitis: Findings at double-contrast barium enema examination. Dis Colon Rectum 1996;39:1204-9.

19. Vaidya M, Sodhi J. Gastrointestinal tract tuberculosis: a study of 102 cases including 55 hemicolectomies. Clin Radiol 1978;29:189-94.

20. Zirinsky K, Auh YH, Kneeland JB, Rubenstein WA, Kazam E. Computed tomography, sonography, and MR imaging of abdominal tuberculosis. J Comput Assist Tomogr 1985;9:961-3.

21. Mirsa S, Mirsa V, Dwivedi M, Gupta SC. Colonic tuberculosis: Clinical features, endoscopic appearance and management. J Gastroenterol Hepatol 1999;14:723-9.

22. Kasulke RJ, Anderson WJ, Gupta SK, Gliedman ML. Primary tuberculous enterocolitis: report of three cases and review of the literature. Arch Surg 1981;116:110-3.

23. Das P, Shukla HS. Clinical diagnosis of abdominal tuberculosis. Br J Surg 1976;63:941-6.

24. Haddad FS, Ghossain A, Sawaya E, Nelson AR. Abdominal tuberculosis. Dis Colon Rectum 1987;30:724-35. 


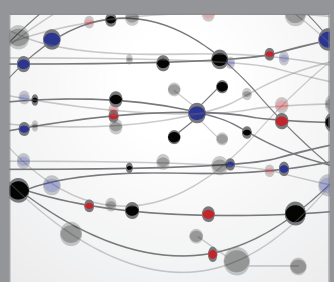

The Scientific World Journal
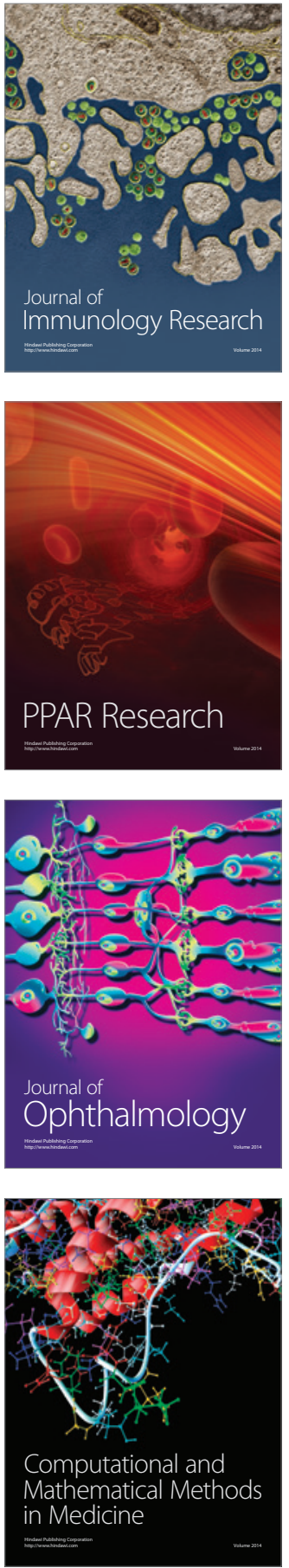

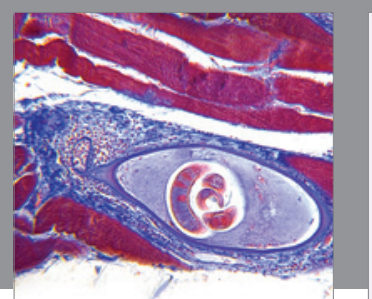

Gastroenterology Research and Practice

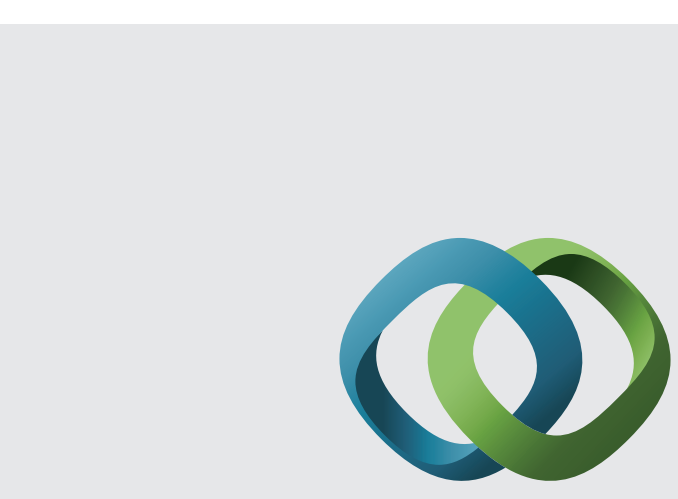

\section{Hindawi}

Submit your manuscripts at

http://www.hindawi.com
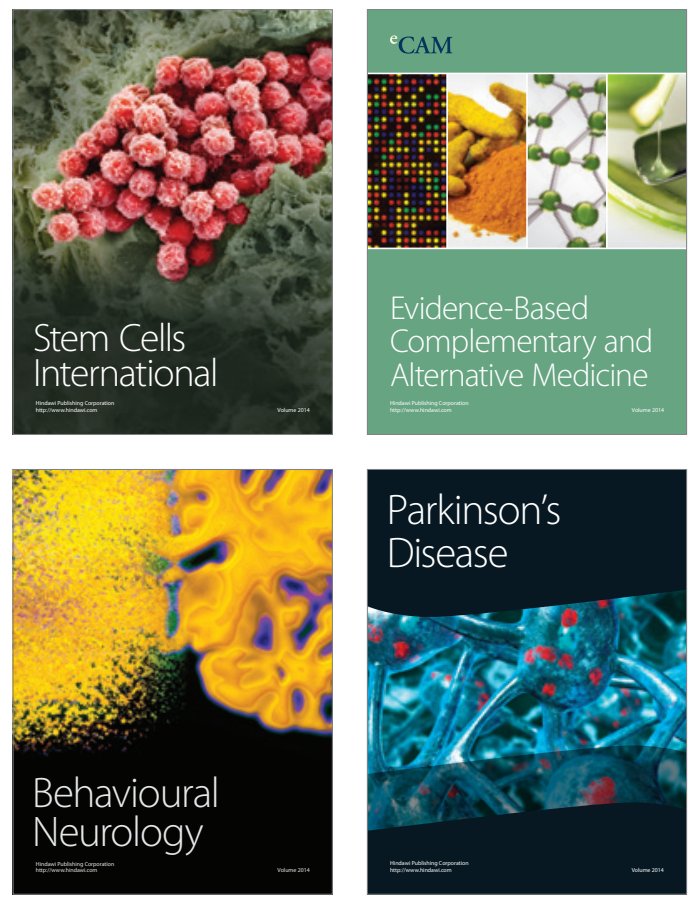
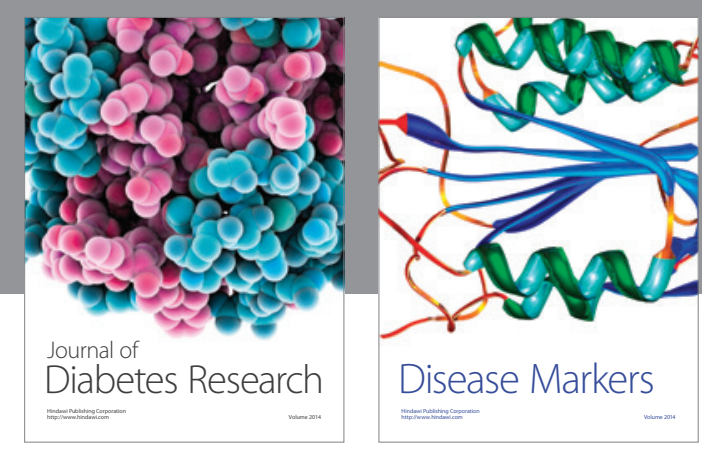

Disease Markers
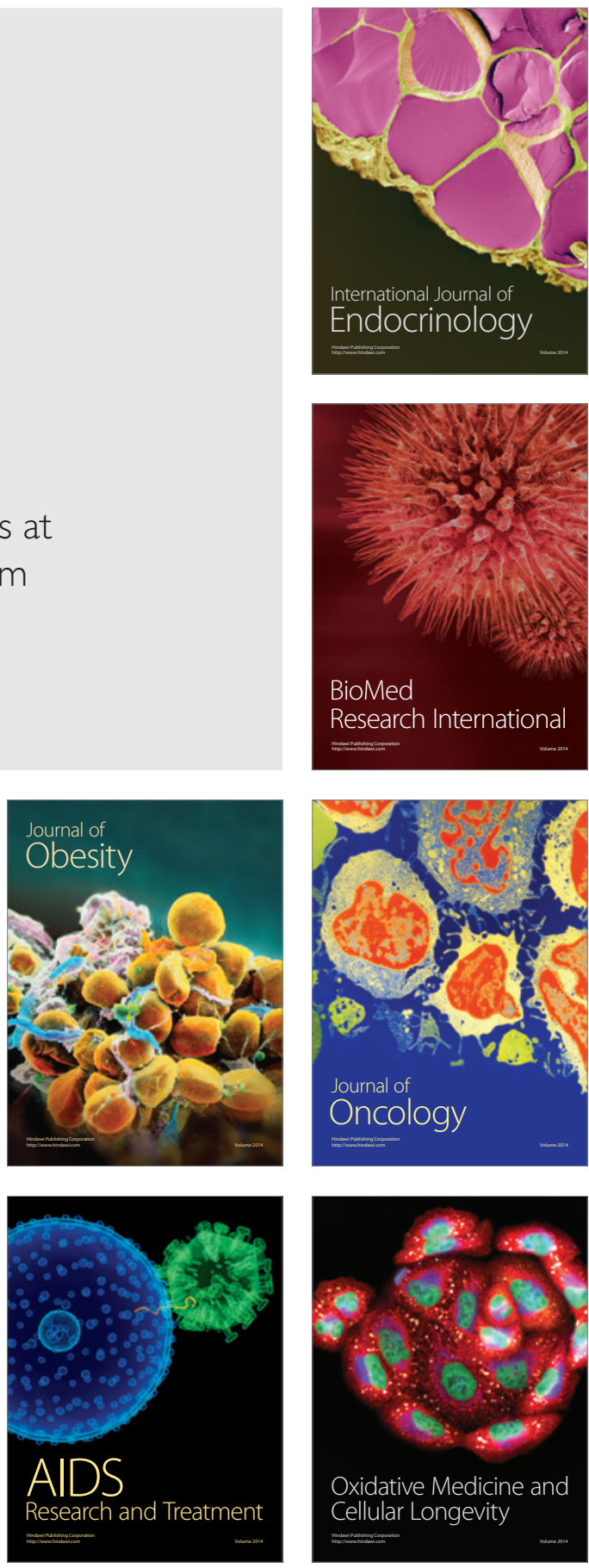